Tropical Journal of Pharmaceutical Research November 2016; 15 (11): 2497-2506

ISSN: $1596-5996$ (print); 1596-9827 (electronic)

(C) Pharmacotherapy Group, Faculty of Pharmacy, University of Benin, Benin City, 300001 Nigeria.

All rights reserved.

Available online at http://www.tjpr.org

Original Research Article

http://dx.doi.org/10.4314/tjpr.v15i11.27

\title{
Ethnobotanical, phytochemical and pharmacological properties of Crinum bulbispermum (Burm f) Milne-Redh and Schweick (Amaryllidaceae)
}

\author{
Alfred Maroyi \\ Department of Botany, University of Fort Hare, Private Bag X1314, Alice 5700, South Africa \\ *For correspondence: Email: amaroyi@ufh.ac.za
}

Received: 6 July $2016 \quad$ Revised accepted: 23 October 2016

\begin{abstract}
Purpose: To present an overview of the ethnobotany, phytochemistry and pharmacology of Crinum bulbispermum so as to understand its importance and potential in primary healthcare systems.

Methods: A review of the literature was undertaken and an in-depth analysis of previous research on ethnobotany, phytochemistry and pharmacology of C. bulbispermum. Literature sources included papers published in journals, reports from international, regional and national organizations, conference papers, books and theses. Electronic search engines such as Google, Google scholar, publishing sites such as Elsevier, scienceDirect, BioMed Central (BMC), PubMed and other scientific database sites such as ChemSpider, PubChem were used.

Results: Crinum bulbispermum is a popular medicinal plant in southern Africa used as remedy for aching joints, rheumatism, kidney or bladder infections, septic sores and wounds. The chemical composition of $\mathrm{C}$. bulbispermum is dominated by various alkaloids and non-alkaloids isolated from the bulbs, flowers, flowering stalks, leaves and roots. Major biological activities demonstrated by $C$. bulbispermum include antimicrobial, antioxidant, actinociceptive, antiplasmodial activities as well as effects on the central nervous system.

Conclusion: The widespread usage of C. bulbispermum as herbal medicine is threatening wild populations, and this calls for conservation strategies and mechanisms for sustainable utilization of the species.
\end{abstract}

Keywords: Actinociceptive, Amaryllidaceae, Antiplasmodial, Crinum bulbispermum, Ethnobotany, Pharmacology, Phytochemistry

Tropical Journal of Pharmaceutical Research is indexed by Science Citation Index (SciSearch), Scopus, International Pharmaceutical Abstract, Chemical Abstracts, Embase, Index Copernicus, EBSCO, African Index Medicus, JournalSeek, Journal Citation Reports/Science Edition, Directory of Open Access Journals (DOAJ), African Journal Online, Bioline International, Open-J-Gate and Pharmacy Abstracts

\section{INTRODUCTION}

Crinum bulbispermum (Burm. f.) Milne-Redh. \& Schweick. is a deciduous bulbous plant which belongs to the Amaryllidaceae family. Crinum bulbispermum was initially described as Amaryllis bulbispermum Burm. f. and then mistakenly identified as Amaryllis longifolia L. which is now Cybistetes longifolia (L.) MilneRedh. \& Schweick. [1-3]. However, MilneRedhead and Schweickerdt [2] simplified the matter in their revision of the genus Ammocharis by suggesting the new combination, $C$. bulbispermum, based on $A$. bulbispermum Burm. [3]. Crinum bulbispermum is a perennial herb growing to about $1 \mathrm{~m}$ tall, with a very large bulb, $10-11 \mathrm{~cm}$ in diameter covered with bases of older leaves and vermiform roots at the base [4]. Crinum bulbispermum has many, thick, stout, simple and glaucous green leaves, measuring $78-92 \mathrm{~cm}$ long, 6-6.7 $\mathrm{cm}$ broad, oblong to linear in shape, acuminate, flat and shining, margin 
slightly scabrous and undulate [3]. The peduncle is $50-90 \mathrm{~cm}$ long and has an umbel with between 6 to 16 flowers, which are white in colour with a dark red keel or entirely suffused with red; the stamens are declinate, white or suffused with pink and the style deep pink in the upper portion with a light brown stigma [4]. Crinum bulbispermum occurs naturally along rivers and streams or in damp depressions in black clay or sandy soils in Lesotho, South Africa and Swaziland [4].

The plant is cultivated throughout the world for its beautiful and trumpet or bell-shaped flowers. Like most medicinal plants in Southern Africa, $C$. bulbispermum is collected from the wild. The unsustainable harvesting of $C$. bulbispermum as herbal medicine and ornamental plant is threatening its continued existence. Although $C$. bulbispermum is widespread in South Africa, its population is declining due to over-exploitation of its bulbs which are sold in the medicinal (muthi) markets in Durban [5,6], Johannesburg [6,7] and Polokwane [8] in South Africa. Raimondo et al [9] categorized $C$. bulbispermum as declining in South Africa based on the modified IUCN Red List Categories and Criteria version 3.1 of threatened species [10-12]. According to Victor and Keith [11] and von Staden et al [12], a species listed as Least Concern (LC) under the IUCN Red List Categories and Criteria version 3.1 [10] can additionally be categorized either as rare, critically rare or declining. The observed population decline of $C$. bulbispermum in South Africa [9] is due to over-exploitation as an ornamental plant, medicinal plant trade and popularity of the species in the medicinal plant (muthi) markets. It is within this context that the current study was carried out, aimed at comprehensively documenting the ethnobotany, phytochemistry and pharmacology of C. bulbispermum so as to highlight research gaps and provide a foundation for further investigations on the plant species.

\section{Traditional medicinal usage}

Crinum bulbispermum is a popular medicinal plant in both rural and urban communities in Southern Africa $[6,7,13,14]$. It is commonly known as Orange river lily in English in South Africa and it is also known by various vernacular and synonym names in different geographical regions in Lesotho, South Africa and Swaziland (see Table 1). In South Africa, the roasted bulbs of C. bulbispermum are applied to aching joints, rheumatism, varicose veins and backache, kidney or bladder infections and are used as poultices for septic sores and abscesses [13]. The southern Sotho in South Africa use the leaves and sliced or crushed bulbs to make a strong brew for treating colds, coughs, and as an external application or wash for wounds, scrofula and haemorrhoids (Table 2). According to Roberts [13], the leaves are used to bind dressings in place and flowers are placed over swollen joints and sprains to reduce swelling. Unspecified parts are used as infusions during pregnancy to ensure easy delivery [15]. The bulbs of C. bulbispermum are used for colds and to stimulate breast milk supplies by the Sotho in Lesotho [16]. Several tribes in Lesotho, South Africa and Swaziland are reported to use the juice squeezed from the base of the leaves to cure earache $[13,17]$. Sometimes pieces of roasted bulb are placed behind the ear or over the ear to ease the pain. Roberts [13] reports that some tribes in South Africa make a brew of the leaves which they believe to be an effective treatment for malaria. This same brew is drunk by the Zulu in South Africa as a treatment for rheumatic fever (usually half a cup chopped leaves in one cup boiling water and strained after standing for five minutes). The Tswana in South Africa drink a brew of crushed leaf bases and stalks to increase the flow of urine in bladder and kidney infections. The sliced bulb is also warmed and applied over the kidneys to ease discomfort [13]. Hutchings [18] records the use of $C$. bulbispermum bulb as a Zulu, Xhosa and Sotho gynaecological remedy and charm. Crinum bulbispermum leaves are browsed by cattle in South Africa [13].

\section{Phytochemistry}

Various reports on the phytochemical screening of C. bulbispermum bulbs, flowers, flowering stalks, leaves and roots confirm the presence of isoquinoline alkaloids, flavonoids, sterols, aldehydes, acids, esters, alcohols, esters, amines and amides, fatty acids and their esters (Table 3). Alkaloids are considered the major bioactive components of $C$. bulbispermum which exhibits various pharmacological effects [24,32,36-41]. Six distinct and structurally diverse isoquinoline alkaloids characteristic of the Amaryllidaceae family [42] have been isolated from C. bulbispermum, namely lycorine-type alkaloid (represented by eight alkaloids, alkaloids 1-8); galanthamine-type alkaloid represented by galanthamine $\mathbf{9}$; cherylline-type alkaloid represented by cherylline 10; crinine-type alkaloid (represented by 29 alkaloids, alkaloids 11-39), tazettine-type alkaloid (represented by 8a-ethoxyprecriwelline39, N-desmethyl-8 $\alpha-$ ethoxypretazettine 40 and $\mathrm{N}$-desmethyl-8ßethoxypretazettine 41) and two minor alkaloids namely augustamine $\mathbf{4 2}$ and trisphaeridine $\mathbf{4 3}$ (Table 3). Non-alkaloid compounds isolated from 
C. bulbispermum bulbs, flowers and leaves are flavonoids represented by 15 compounds (compounds 44-58); sterols represented by dihydrositosterol 59 and stigmasterol 60; aldehydes, acids and esters represented by $4,5-$ methylenedioxy-4'-hydroxy-2-aldehyde-(1,1'-

biphenyl) 61 and $\rho$-hydroxybenzene acetic acid ethyl ester 62; alcohols, esters, amines and amides represented by $\beta$-(3,4-dimethoxyphenyl)$\alpha, \beta$-ethanediol 63 and choline 64; and fatty acids and their esters represented by nine compounds, compounds 65-73 (see Table 3). Although very little pharmacological evaluation of non-alkaloid compounds isolated from $C$. bulbispermum has been done to date, flavonoids are known to exhibit antioxidant activity, free radical scavenging capacity, coronary heart disease prevention, hepatoprotective, anti-inflammatory, anticancer and antiviral activities [43]. While phytosterols are known to have bioactive prevention properties such as lowering of cholesterol levels [44] and cancer prevention [45] properties. Previous research by Li et al [46] showed that unsaturated fatty acids have antifungal potencies, low toxicities and good pharmaceutical properties.

\section{Pharmacological activities}

A number of pharmacological activities of $C$. bulbispermum have been reported in literature justifying some of its ethnomedicinal uses. Some of the listed pharmacological activities may not relate directly to the ethnomedicinal uses of $C$. bulbispermum, but may provide some insight into its potential therapeutic value and bioactive properties. A wide range of biological activities have been reported including antimicrobial [36], antinociceptive [37], antiplasmodial [38], antioxidant $[37,39]$, cytotoxicity and anti-apoptotic $[24,37,40,41]$ as well as effects on the central nervous system (CNS) [37].

\section{Effects on the central nervous system (NCS)}

In recent years, members of the Amaryllidaceae family have been shown to contain alkaloids with promising acetylcholinesterace (AChE) inhibiting properties $[47,48]$. Adewusi and Steenkamp [39] found ethyl acetate extracts of $C$. bulbispermum bulbs and roots as well as methanol bulb extract to have some level of inhibitory activity against AChE with $\mathrm{IC}_{50}$ values of $0.0021 \pm 0.007,0.0393$ \pm 0.014 and $0.0148 \pm 0.039 \mathrm{mg} / \mathrm{mL}$, respectively.

Table 1: Vernacular names and synonyms of Crinum bulbispermum

\begin{tabular}{lll}
\hline Vernacular name(s) with ethnic group/geographical region in brackets & Country & Reference \\
\hline Lelutla, mototse (Sesotho) & Lesotho & {$[20]$} \\
Orange rivierle lie, Vaalrivierle lie, Vleilelie (Afrikaans), Orange river lily, wild & South Africa & {$[5,6,8,14]$} \\
amaryllis (English), lelutla, mototse (Sotho), mduze, umduze, umduzi, & & \\
umnduze (Zulu) & Swaziland & {$[19]$} \\
Umnduze (Swazi) & \\
Synonym & {$[4]$} \\
Amaryllis bulbispermum Burm. f. & {$[4]$} \\
Amaryllis longifoliasensu Jacq. & {$[4]$} \\
Amaryllis longifolia var. riparia Ker-Gawl. & {$[4]$} \\
Crinum capense sensu Herb. & {$[4]$} \\
Crinum longifolium (L.) Thunb. & {$[4]$} \\
Crinum riparium Herb. & & \\
\hline
\end{tabular}

Table 2: Ethnomedicinal uses of Crinum bulbispermum in Southern Africa

\begin{tabular}{lll}
\hline Use & Country practised & References \\
\hline Abscesses and sores & South Africa & {$[17]$} \\
Aching joints & South Africa & {$[13]$} \\
Backache & South Africa & {$[17]$} \\
Binding for dressings & South Africa & {$[17]$} \\
Charm & Lesotho; South Africa & {$[16,18]$} \\
Colds & Lesotho; South Africa & {$[13]$} \\
Coughs & Lesotho; South Africa & {$[13]$} \\
Earache & South Africa & {$[17]$} \\
Gynaecological remedy & South Africa & {$[18]$} \\
Haemorrhoids & South Africa & {$[13,17]$} \\
Kidney and bladder infections (increase urine flow) & South Africa & {$[17]$} \\
Malaria & South Africa & {$[17]$} \\
Reduce swelling of swollen joints and sprains & South Africa & {$[17]$} \\
Scrofula & South Africa & {$[13]$} \\
Varicosities & South Africa & {$[17]$} \\
Wounds & South Africa & {$[13]$} \\
\hline
\end{tabular}


Table 3: Alkaloids and non-alkaloids isolated and characterized from Crinum bulbispermum

\begin{tabular}{|c|c|c|c|}
\hline S/No. & Alkaloid & Plant part & References \\
\hline & Lycorine-type alkaloid & & \\
\hline 1 & Lycorine & Bulbs, flowering stalks, roots & {$[21,22]$} \\
\hline 2 & 1, 2-di-O-acetyllycorine & Bulbs & [23] \\
\hline 3 & 8-hydroxylycorine-7-one & Bulbs & [24] \\
\hline 4 & Hippacine & Bulbs & [25] \\
\hline 5 & Hippadine (pratorine) & Bulbs & [21] \\
\hline 6 & Hippamine & Bulbs & [24] \\
\hline 7 & Pratorinine & Bulbs & {$[26,27]$} \\
\hline \multirow[t]{2}{*}{8} & Protorimine & Bulbs & [28] \\
\hline & Galanthamine-type alkaloid & & \\
\hline \multirow[t]{2}{*}{9} & Galanthamine & Bulbs & {$[26,27]$} \\
\hline & Cherylline-type alkaloid & & \\
\hline 10 & $\begin{array}{l}\text { Cherylline } \\
\text { Crinine-type alkaloid }\end{array}$ & Bulbs & [23] \\
\hline 11 & Crinine & Bulbs & {$[22,23]$} \\
\hline 11 & 3-O-Acetyl-crinine (krepowine) & Bulbs & {$[23,28]$} \\
\hline 12 & 3-O-acetylhamayne & Bulbs, flowering stalks, roots & {$[29,30]$} \\
\hline 13 & 3-O-acetyl-powelline & Bulbs & [28] \\
\hline 14 & 3,4-anhydropowelline & Bulbs & [28] \\
\hline 15 & 6-hydroxycrinamine & Bulbs, flowering stalks, roots & [30] \\
\hline 16 & 11-hydroxyvittatine & Bulbs & [24] \\
\hline 17 & Bowdensine & Bulbs & [23] \\
\hline 18 & Bulbisine & Bulbs & {$[28]$} \\
\hline 19 & Bulbispermine & Bulbs, flowering stalks, roots & {$[29,31]$} \\
\hline 20 & buphanamine & Bulbs & {$[26,27]$} \\
\hline 21 & Buphanidrine-6- $\beta$-ethoxy & Bulbs & [28] \\
\hline 22 & Buphanisine & Bulbs & {$[28]$} \\
\hline 23 & Buphanisine-6-a-hydroxy & Bulbs & {$[28,32]$} \\
\hline 24 & Buphanisine-6- $\beta$-hydroxy & Bulbs & [28] \\
\hline 25 & Buphanisine-6- $\alpha$-ethoxy & Bulbs & [28] \\
\hline 26 & Crinalbine & Bulbs & [21] \\
\hline 27 & Crinamidine & Bulbs & [23] \\
\hline 28 & Crinamine & Bulbs, flowering stalks, roots & {$[21-23,30]$} \\
\hline 29 & Crinamine-6-a-hydroxy & Bulbs, flowering stalks, roots & {$[22,29]$} \\
\hline 30 & Crinamine- $6-\beta$-hydroxy & Bulbs, flowering stalks, roots & {$[22,29]$} \\
\hline 31 & Crinine-6-a-hydroxy & Bulbs & [28] \\
\hline 32 & Crinine-6- $\beta$-hydroxy & Bulbs & [28] \\
\hline 33 & Crinine-6- $\alpha-e t h o x y$ & Bulbs & [28] \\
\hline 34 & deacetylbowdensine & Bulbs & [23] \\
\hline 35 & Hamayne & Bulbs & {$[21,31]$} \\
\hline 36 & Powelline & Bulbs & {$[22,23]$} \\
\hline 37 & Powelline-6- $\alpha$-ethoxy & Bulbs & [28] \\
\hline \multirow[t]{2}{*}{38} & Vittatine & Bulbs & {$[26,27]$} \\
\hline & Tazettine type alkaloid & & \\
\hline 39 & 8a-ethoxyprecriwelline & Bulbs, flowering stalks, roots & [29] \\
\hline 40 & $\mathrm{~N}$-desmethyl-8a-ethoxypretazettine & Bulbs, flowering stalks, roots & [29] \\
\hline 41 & $\begin{array}{l}\text { N-desmethyl-8ß-ethoxypretazettine } \\
\text { Other minor alkaloids }\end{array}$ & Bulbs, flowering stalks, roots & [29] \\
\hline 42 & Augustamine & Bulbs & {$[28,32]$} \\
\hline \multirow[t]{2}{*}{43} & Trisphaeridine & Bulbs & [28] \\
\hline & $\begin{array}{l}\text { Non alkaloid compounds } \\
\text { Flavonoids }\end{array}$ & & \\
\hline 44 & 4'-hydroxy-7-methoxy-flavan & Bulbs & [28] \\
\hline 45 & 2(S)3',4'-dihydroxy-7-methoxy-flavan & Bulbs & [25] \\
\hline 46 & 4'-dihydroxy-7-methoxy-flavan-3-ol & Bulbs & {$[25]$} \\
\hline 47 & 7,4'-dihydroxy-flavanone[(-)-liquiritigenin] & Bulbs & {$[25]$} \\
\hline 48 & 7'-hydroxy-8-methoxy-flavanone[Isolarrien] & Bulbs & {$[25]$} \\
\hline 49 & 4'-hydroxy-7-methoxy-flavone & Bulbs & [33] \\
\hline 50 & 4,4'-dihydroxy-2-methoxy-chalcone & Bulbs & [33] \\
\hline 51 & 2',4,4'-trihydroxy-chalcone(Isoliquiritigenin) & Bulbs & [25] \\
\hline 52 & 4-hydroxy-2',4'-dimethoxy-dihydrochalcone & Bulbs & [25] \\
\hline
\end{tabular}


Table 3: Alkaloids and non-alkaloids isolated and characterized from Crinum bulbispermum (Continued)

\begin{tabular}{|c|c|c|c|}
\hline S/No. & Alkaloid & Plant part & References \\
\hline 53 & $\begin{array}{l}\text { Isorhamnetin-3-O-glucoside(3'-methyl-quercetin } \\
\text { glucoside) }\end{array}$ & Flowers & [34] \\
\hline 54 & Kaempferol-3-O-glucoside & Flowers & [34] \\
\hline 55 & Kaempferol-3-xyloside & Leaves & [31] \\
\hline 56 & $\begin{array}{l}\text { Kaempferol-3-O- } \beta-D \text {-xylopyranosyl }(1 \rightarrow 3) \beta-D \text { - } \\
\text { glucopyranoside }\end{array}$ & Flowers & {$[34]$} \\
\hline 57 & Quercetin-3-O-glucoside & Flowers & [34] \\
\hline 58 & $\begin{array}{l}\text { Quercetin-3-O- } \beta \text {-D-(6-O-acetylglucopyranosyl) }(1 \rightarrow 3) \beta-D \text { - } \\
\text { glucopyranoside } \\
\text { Sterols }\end{array}$ & Flowers & [34] \\
\hline 59 & Dihydrositosterol & Bulbs, leaves & [35] \\
\hline 60 & $\begin{array}{l}\text { Stigmasterol } \\
\text { Aldehydes, acids and esters }\end{array}$ & Bulbs, leaves & [35] \\
\hline 61 & 4,5-methylenedioxy-4'-hydroxy-2-aldehyde-(1,1'-biphenyl) & Bulbs & [25] \\
\hline 62 & $\begin{array}{l}\rho \text {-hydroxybenzene acetic acid ethyl ester } \\
\text { Alcohols, esters, amines and amides }\end{array}$ & Bulbs & [33] \\
\hline 63 & $\beta$-(3,4-dimethoxyphenyl)- $\alpha, \beta$-ethanediol & Bulbs & [33] \\
\hline 64 & $\begin{array}{l}\text { Choline } \\
\text { Fatty acids and their esters }\end{array}$ & Bulbs & [21] \\
\hline 65 & Linoleic acid & Bulbs & [35] \\
\hline 66 & Linoleic acid methyl ester & Bulbs, leaves & [35] \\
\hline 67 & Oleic acid & Bulbs, leaves & [35] \\
\hline 68 & Palmitic acid & Bulbs, leaves & [35] \\
\hline 69 & Palmitic acid methyl ester & Bulbs, leaves & [35] \\
\hline 70 & n-Hexacosane & Bulbs, leaves & [35] \\
\hline 71 & n-Heptacosane & Bulbs, leaves & [35] \\
\hline 72 & n-Nonacosane & Bulbs, leaves & [35] \\
\hline 73 & n-Pentacosane & Bulbs, leaves & [35] \\
\hline
\end{tabular}

In an earlier research, orally administered aqueous leaf extract of $C$. bulbispermum doses of $1,1.5$ and $3 \mathrm{~g} / \mathrm{kg}$ showed central inhibitory activity and markedly impaired the four parameters of rat hold-board test indicating its sedative properties [37]. The ability of $C$. bulbispermum to inhibit acetylcholinesterase may be ascribed to several alkaloids which have been isolated from the plant species (Table 3) indicating its potential for use in treatment of neurodegenerative diseases. Recently, the alkaloid galanthamine $\mathbf{9}$ isolated from $C$. bulbispermum (Table 3) was approved in the United States, many European countries and many Asian countries for the treatment of Alzheimer's disease (AD) [49]. Alzheimer's disease is characterized by a progressive impairment of cognitive functions including loss of memory and the inability to perform basic daily life activities [48]. Based on the cholinergic hypothesis, these symptoms are the results of the reduction in brain acetylcholine activity due to the catabolism of acetylcholine by ACHE [48]. Other alkaloids isolated from C. bulbispermum which have been screened for AChE inhibition activity include crinine 11 which exhibited inhibitory activity with $\mathrm{IC}_{50}$ of $461 \mu \mathrm{M}$, crinamine $28\left(\mathrm{IC}_{50}=300 \mu \mathrm{M}\right.$ and lycorine $1\left(\mathrm{IC}_{50}=213 \mu \mathrm{M}\right)$ [48].

\section{Antioxidant activity}

A methanol bulb extract of $C$. bulbispermum showed some radical scavenging activity in ABTS assays with $\mathrm{IC}_{50}$ value of $0.0685 \pm 0.041$ $\mathrm{mg} / \mathrm{mL}$ [39]. The total phenolic, flavonol and flavonoid contents of $C$. bulbispermum roots were relatively high for both solvents tested with total phenol of $202.38 \pm 0.50 \mathrm{mg}$ tannic acid $/ \mathrm{g}$, flavonol (20.79 $\pm 0.10 \mathrm{mg}$ quercetin/g) and flavonoid (9.18 $\pm 0.50 \mathrm{mg}$ quercetin/g) [39]. The levels of these phenolic compounds are an indication of the potential antioxidant activity of the plant extracts as phenolic compounds are well known as radical scavengers, metal chelators, reducing agents, hydrogen donors and singlet oxygen quenchers [50,51]. Additionally, the leaf extracts of $C$. bulbispermum showed modest antioxidant activity with $\mathrm{EC}_{50}$ value of $203.76 \mu \mathrm{g} / \mathrm{mL}$ which was assessed by the thiobarbituric acid reactive substances assay [37]. These findings support the traditional use of the plant species for treating neurological disorders especially those involving cholinesterase mechanism and reactive oxygen species.

\section{Antinociceptive activity}


Ratnasooriya et al. [37] evaluated the antinociceptive activity of C. bulbispermum leaves using three models of nociception namely tail flick, hot plate and formalin tests in male rats. The results showed that the leaf extracts had marked antinociceptive potential, particularly, when evaluated in the formalin test. According to Ratnasooriya et al [37], the obtained results suggest that the antinociception is mediated both spinally and supraspinally and is effective against phasic and continuous non-inflammatory or inflammatory pain. Ratnasooriya et al [37] attributed the antinociception of the leaf extract of C. bulbispermum to the results of opioid mechanisms, sedation and antioxidant activities of the species. These results support the traditional use of the species in various inflammatory ailments and diseases ranging from microbial infection to injury that result in swelling, cell injury and death.

\section{Antiplasmodial activity}

Van Dyk et al [38] screened C. bulbispermum for antiplasmodial activity using the $[3 \mathrm{H}]-$ hypoxanthine incorporation assay against the chloroquine-resistant Plasmodium falciparum. Extracts of $C$. bulbispermum had $I_{50}$ values $\leq 1$ $\mu \mathrm{g} / \mathrm{mL}$ with the ethyl acetate extracts of the roots and bulbs having values comparable to chloroquine $(0.04 \mu \mathrm{g} / \mathrm{mL})$. Van Dyk et al [38] identified lycorine $\mathbf{1}$ as a potent antiplasmodial compound with an $\mathrm{IC}_{50}$ value of $0.03 \mu \mathrm{g} / \mathrm{mL}$ against the chloroquine-resistant strain (FCR-3) of $P$. falciparum, which is comparable to the activity of the crude extract and chloroquine. The most promising extract was the ethyl acetate bulb extract of $C$. bulbispermum with an $I_{50}$ value of $0.08 \mu \mathrm{g} / \mathrm{mL}$ and a security index of 2203.13. Likhitwitaywuid et al [52] reported an $\mathrm{IC}_{50}$ value of $0.3 \mu \mathrm{g} / \mathrm{mL}$ for lycorine 1 isolated from $C$. amabile against the chloroquine-resistant strain (W-2).

\section{Antimicrobial activity}

Griffiths [36] assessed antimicrobial activity of $C$. bulbispermum using the direct plate method and minimum inhibitory concentration values were determined. The best activity was observed for the alkaloid lycorine $\mathbf{1}$ against Bacillussubtilis [36]. One of the most common ethnomedicinal uses of $C$. bulbispermum is in the treatment of a wide range of infectious diseases caused by microorganisms such diseases or ailments include symptoms such as sores [17] and wounds [13]. Previous research showed that some of the alkaloids that have been isolated from C. bulbispermum have antibacterial activity. For example, the alkaloid crinamine $\mathbf{2 8}$ is known to have antibacterial activity, as it showed some strong activity against Bacillus subtilis and Staphylococcus aureus [53].

\section{Cytotoxicity and anti-apoptotic activity}

Seoposengwe et al [41] evaluated the cytoprotective potential of C. bulbispermum, after induction of toxicity using rotenone, in SH-SY5Y neuroblastoma cells. Rotenone reduced intracellular reactive oxygen species (ROS) levels after $24 \mathrm{~h}$ exposure. Pre-treating cells with C. bulbispermum extracts reversed the effects of rotenone on intracellular ROS levels. Rotenone exposure also decreased intracellular glutathione levels, which was counteracted by pre-treatment with any one of the extracts. MMP was reduced by rotenone, which was neutralized by pretreatment with $C$. bulbispermum ethyl acetate extract. All extracts inhibited rotenone-induced activation of caspase-3. Crinum bulbispermum demonstrated anti-apoptotic activity and restored intracellular glutathione content following rotenone treatment, suggesting that they may possess neuroprotective properties.

Ratnasooriya et al [37] evaluated the sub-chronic toxicity of the aqueous leaf extract of $C$. bulbispermum. The extract induced mild to moderate toxicity in rats which developed diarrhoea and postural abnormalities on the second day, and two rats died by the fourth day. Liver and renal toxicities (increase of serum SGOT, SGPT, creatinine and urea) were also reported and the authors attributed this toxicity to the lycorine- and crinine-types of alkaloids present in $C$. bulbispermum (see Table 3). According to van Wyk et al [54] the major toxic compound in $C$. bulbispermum is the alkaloid crinamine 28, which is regarded as highly lethal with an oral lethal dose $L D_{50}$ at a concentration of $10 \mathrm{mg} / \mathrm{kg}$ body weight in dogs. Crinamine 28 is regarded as a powerful transient hypotensive in dogs and also shows respiratory depressant activity [55]. Similarly, Aboul-Ela et al [24] tested cytotoxicity of $C$. bulbispermum bulbs using the brine shrimp bioassay. The most effective one were the butanol fraction of the acidic extract of the non-flowering bulbs with $\mathrm{LD}_{50}$ of $63.1 \mu \mathrm{g} / \mathrm{mL}$ followed by the ether fraction of the alkaline extract of the flowering bulbs with $L_{50}$ of 73 $\mu \mathrm{g} / \mathrm{mL}$.

Van Dyk et al [38] evaluated the cytotoxicity of $C$. bulbispermum compounds as determined by in vitro cellular toxicity assay, reporting the $\mathrm{IC}_{50}$ value of $445.47 \mu \mathrm{g} / \mathrm{mL}$ for lycorine 1 against human kidney epithelial cells and toxicity index of $>15$ 000. Other researchers like Campbell et al [56] evaluated cytotoxicity activities of alkaloids 
associated with $C$. bulbispermum reporting $I_{50}$ values of 0.6 and $0.7 \mu \mathrm{g} / \mathrm{mL}$ for lycorine 1 against the strains $\mathrm{D}-10$ and $\mathrm{FAC} 8$, respectively. Likhitwitaywuid et al [52] reported $\mathrm{IC}_{50}$ values for ranging from 0.3 to $1.6 \mu \mathrm{g} / \mathrm{mL}$ against a series of human cancer cells. The anti-cancer activity of lycorine 1 was also reported by Li et al [57] as an effect due to the apoptosis inducing effect of lycorine 1 and it has been found to inhibit protein synthesis. Abd El Hafiz et al [32] examined the constituents of $C$. bulbispermum for activity against human leukemic Molt 4 cells. Of the flavan, 4'-hydroxy-7-methoxyflavan 44 and three crinanes namely powelline 36, crinine-6- $\alpha-$ hydroxy 31 and buphanisine-6-a-hydroxy 23 tested, only buphanisine-6-a-hydroxy 23 and 4'hydroxy-7-methoxyflavan 44 were moderately active, causing a steady decline (up to about 20 $\%$ ) in the viability of leukemia cells over the three-day treatment period at a dosage of 71 $\mu \mathrm{g} / \mathrm{mL}$.

Seoposengwe et al [41] found the ethyl acetate extract of $C$. bulbispermum to have the least cytotoxic with an $\mathrm{LC}_{50}$ value of $>100 \mu \mathrm{g} / \mathrm{mL}$. Contrary to this, the methanol extract produced an $\mathrm{LC}_{50}$ value of $46.18 \pm 0.91 \mu \mathrm{g} / \mathrm{mL}$. Adewusi et al [40] evaluated cytotoxicity of $C$. bulbispermum ethanol extracts against SH-SY5Y (human neuroblastoma) cells as well as toxically induced with $A \beta$, using the MTT and neutral red uptake assays. The extracts of the root and bulb of $C$. bulbispermum were the most toxic with $I_{50}$ values $<50 \mu \mathrm{g} / \mathrm{mL}$ in both assays. However, despite the observed toxicity, the roots and bulbs of $C$. bulbispermum still reduced the cell death induced by $A \beta$ at less toxic doses. These results show that $C$. bulbispermum may contain several alkaloids with possible neuroprotective activities.

\section{FINAL REMARKS}

The widespread usage of $C$. bulbispermum as an ornamental plant and in traditional medicine resulting in negative impact on wild populations calls for conservation strategies and mechanisms for sustainable utilization of the species. The estimated declining rate of $C$. bulbispermum [9] is based on the decreasing population numbers at known habitat sites and reduction in the bulb sizes of the species sold in medicinal muthi markets [7]. Therefore, propagation protocols for C. bulbispermum should be developed as an alternative and viable means to provide sufficient plants to meet the demand for ornamental and medicinal purposes and at the same time protecting the natural populations. There is also need for comparative evaluation of the phytochemistry and biological activities of the various plant parts in an attempt to suggest plant part substitution as a means of conserving this highly collected plant species. If phytochemical and biological analyses prove that the leaves, flower stalks, flowers and fruits have comparable properties and activities to those of the bulbs and roots, then plant part substitution can be used to curtail the destructive harvesting of bulbs that has led to a continuous decimation of the wild populations.

The present review summarizes ethnomedicinal uses, phytochemistry, biological activities and cytotoxicity of different extracts and compounds of $C$. bulbispermum. Crinum bulbispermum has been traditionally used as herbal medicine throughout its distributional range in southern Africa, used for the treatment of common diseases and ailments like colds, cough, earache, haemorrhoids, malaria, wounds and others medical complications like gynaecological, kidney and bladder problems. Recent research on C. bulbispermum focused primarily on evaluating the antimicrobial, antioxidant, antiplasimodial, cytotoxicity activities of the species as well as the effects on the central nervous system. Alkaloids appear to be the major ingredients in $C$. bulbispermum bulbs, flowers, flower stalks, leaves and roots and these compounds appear to be responsible for the pharmacological properties of the species. Other important phytochemical constituents isolated from C. bulbispermum bulbs, flowers and leaves are flavonoids, sterols, aldehydes, acids and esters, alcohols, esters, amines, amides and fatty acids and their esters. Surprisingly, there is no systematic data linking the ethnomedicinal uses of $C$. bulbispermum to the phytochemical and pharmacological properties of these nonalkaloid compounds. Future studies should therefore, try to establish a link between the phytochemical and pharmacological properties of the non-alkaloid compounds and the ethnomedicinal uses of C. bulbispermum.

Although contemporary research involving $C$. bulbispermum is promising, it is too preliminary and sometimes too general to be used to explain and support its ethnomedicinal uses. Most of the mentioned phytochemical constituents and pharmacological studies have provided some suggestive scientific evidence for the various ethnomedicinal uses of $C$. bulbispermum in the treatment of parasitic diseases such as control and management of malaria, inflammatory ailments and wounds; there is need for extensive phytochemical, pharmacological, preclinical and clinical research. There is yet not enough

Trop J Pharm Res, November 2016; 15(11): 2503 
systematic data regarding the pharmacokinetics and clinical research of $C$. bulbispermum products and compounds. There are very few to nil experimental animal studies, randomized clinical trials and target-organ toxicity studies involving $C$. bulbispermum and its derivatives that have been carried out so far. Therefore, studies should identify the bioactive components, details of the molecular modes or mechanisms of action, pharmacokinetics and physiological pathways for specific bioactives of $C$. bulbispermum. Future studies should include the identification of any side effects and/or toxicity.

\section{DECLARATIONS}

\section{Acknowledgement}

Financial support of this work by the National Research Foundation (NRF) and Govan Mbeki Research and Development Centre (GMRDC), University of Fort Hare is gratefully acknowledged.

\section{Conflict of Interest}

No conflict of interest associated with this work.

\section{Contribution of Authors}

The authors declare that this work was done by the authors named in this article and all liabilities pertaining to claims relating to the content of this article will be borne by them.

\section{Open Access}

This is an Open Access article distributed under the terms of the Creative Commons Attribution License, which permits unrestricted use, distribution, and reproduction in any medium, provided the original work is properly credited.

\section{REFERENCES}

1. Baker JG. Amaryllidaceae. In: Thiseton-Dyer WT (ed.). Flora Capensis: Systematic Description of the Plants 1896; 6: 171-246.

2. Milne-Redhead E, Schweickerdt HG. A new conception of the genus Ammocharis Herb. Bot J Lin Soc 1939; 52: 159-197.

3. Verdoorn IC. Crinum bulbispermum. In: Dyer RA (ed.). The Flowering Plants of South Africa. Botanical Research Institute, Pretoria; 1953. $p 1150$.

4. Verdoorn IC. The genus Crinum in Southern Africa. Bothalia 1973; 11: 27-52.
5. Cunningham AB. An investigation of the herbal medicine trade in Natal/KwaZulu. Investigational Report, vol 29. Institute of Natural Resources. Pietermaritzburg; 1988.

6. Williams V, Balkwill K, Witkowski ETF. A lexicon of plants traded in the Witwatersrand uMuthi shops, South Africa. Bothalia 2001; 31(1): 71-98.

7. Williams VL. The design of a risk assessment model to determine the impact of the herbal medicine trade on the Witwatersrand on resources of indigenous plant species. PhD thesis. University of the Witwatersrand; 2007.

8. Moeng TE. An investigation into the trade of medicinal plants by muthi shops and street vendors in the Limpopo province, South Africa. MSc dissertation, University of Limpopo, Sovenga; 2010.

9. Raimondo $D$, von Staden L, Foden W, Victor JE, Helme NA, Turner RC, Kamundi DA, Manyama PA. Red list of South African plants. Strelitzia, 25. South African National Biodiversity Institute, Pretoria; 2009.

10. International Union for Conservation of Nature (IUCN). IUCN Red List Categories and Criteria. Version 3.1. 2nd ed. Gland, IUCN; 2012.

11. Victor JE, Keith M. The Orange list: A safety net for biodiversity in South Africa. S Afr J Sci 2004; 100: 139141.

12. von Staden L, Raimondo D, Foden W. Approach to Red List assessments. In: Raimondo D, von Staden L, Foden W, Victor JE, Helme NA, Turner RC, Kamundi DA, Manyama PA (eds.). Red List of South African plants. Strelitzia, 25. South African National Biodiversity Institute, Pretoria; 2009. p. 6-16.

13. Roberts M. Indigenous healing plants. Southern Book, Halfway House, Johannesburg; 1990.

14. Hutchings $A$, Scott $A H$, Lewis G, Cunningham A. Zulu medicinal plants. An inventory. University of Natal Press, Scottsville, Pietermaritzburg; 1996.

15. Gerstner J. A preliminary checklist of Zulu names of plants with short notes. Bantu Studies 1941; 15(3): 277301.

16. Jacot Guillarmod AJ. Flora of Lesotho (Basutoland). Cramer, Lehre; 1971.

17. Watt JM, Breyer-Brandwijk MG. The medicinal and poisonous plants of southern and Eastern Africa: Uses, chemical composition, pharmacological effects and toxicology in man and animals. E. and S. Livingstone Ltd., Edinburgh; 1962.

18. Hutchings A. A survey and analysis of traditional medicinal plants as used by the Zulu, Xhosa and Sotho. Bothalia 1989; 19: 111-123.

19. Singwane SS, Shabangu N. An examination of the utilization and management of natural woodlands in Swaziland: A case of Ka Bhudla community. J Sust Develop Africa 2012; 14, No.1. (accessed 10.06.2016). Available from: http://www.jsdafrica.com/Jsda/Vol14No1-Spring2012A/PDF.

20. Moteetee $A$, van Wyk B-E. The medical ethnobotany of Lesotho: A review. Bothalia 2011; 41: 209-228. 
21. El-Moghazi AM, Ali AA. Investigation of the alkaloidal constituents of Crinum bulbispermum, Part II: Isolation and identification of crinamine and other three alkaloids. Planta Med 1976; 29: 156-159.

22. Elgorashi EE, Drewes SE, Morris C, Van Staden J. Variation among three Crinum species in alkaloid content. Bioch Syst Ecol 2003; 31(6): 601-615.

23. Kobayashi S, Tokumoto T, Kihara M, Imakura Y, Shingu T, Talra Z. Alkaloids constituents of Crinum latifolium and Crinum bulbispermum (Amaryllidaceae). Chem Pharm Bull 1984; 32: 3015-3022.

24. Aboul-Ela MA, El-Lakany AM, Hammoda HM. Alkaloids from the bulbs of Crinum bulbispermum. Pharmazie 2004; 59: 894-895.

25. Ramadan MA, Kamel MS, Ohtani K, Kasai R, Yamasaki K: Minor phenolics from Crinum bulbispermum Miln. bulbs. Phytochemistry 2000; 54(8): 891-896.

26. Ali AA, Ramadan MA, Frahm AW. Alkaloidal constituents of Crinum bulbispermum. III: Bulbispermine, a new alkaloid of Crinum bulbispermum. Planta Med 1984; 50 : 424-427.

27. Viladomat F, Bastida J, Codina C, Nair JJ, Campbell WE. Alkaloids of the South African Amaryllidaceae. In: Pandalai SG (ed.). Recent research developments in phytochemistry, vol 1. Research Signpost Publishers, Trivandrum; 1997. p. 131-171.

28. Ramadan MA. Phytochemical investigation of the minor alkaloids and phenolic compounds of Crinum bulbispermum Milne. and Crinum augustum Rox. cultivated in Egypt. PhD Thesis, Assiut University; 1986.

29. Elgorashi EE, Drewes SE, van Staden J. Alkaloids from Crinum bulbispermum. Phytochemistry 1999; 52(3): 533-536.

30. Elgorashi EE. Alkaloids from three South African Crinum Species. PhD Thesis, University of Natal, Pietermaritzburg; 2000.

31. Ali AA, El-Moghazy, AM, Ross SA, El-Shanawany MA. Phytochemical studies on some Amaryllidaceae plants cultivated in Egypt. Fitoterapia 1981; 52(5): 209-212.

32. Abd El Hafiz MA, Ramadan MA, Jung ML, Beck JP, Anton R. Cytotoxic activity of Amaryllidaceae alkaloids from Crinum bulbispermum. Planta Medica 1991; 57: 437-439.

33. Khalifa $A A$. Non-alkaloidal constituents from Crinum bulbispermum bulbs. Bull Pharm Sci (Assiut University) 2001; 24(1): 41-46.

34. Abou Donia AH, Abou-Ela MA, Hammoda HM, Kashaba $A A$. Flavonol glucosides from the flowers of Crinum bulbispermum. Alexandria J Pharm Sci 2005; 19(2): 153-157.

35. Tram NT, Titorenkova T, Bankova V, Handjieva N, Popov SS. Crinum L. Amaryllidaceae. Fitoterapia 2002; 73(3): 183-208.

36. Griffiths S. Antimalarial compounds from Crinum bulbispermum. MSc Dissertation. North West University, Potchefstroom; 2004

37. Ratnasooriya WD, Deraniyagala SA, Bathige SDNK, Hettiarachchi HDI. Leaf extract of Crinum bulbispermum has antinociceptive activity in rats. J Ethnopharmacol 2005; 97: 123-128.

38. van Dyk S, Griffiths S, van Zyl RL, Malan SF. The importance of including toxicity assays when screening plant extracts for antimalarial activity. Afr $J$ Biotechn 2009; 8: 5595-5601.

39. Adewusi EA, Steenkamp V. In vitro screening for acetylcholinesterase inhibition and antioxidant activity of medicinal plants from southern Africa. Asian Pacific $J$ Trop Med 2011; 4: 829-835.

40. Adewusi EA, Fouche G, Steenkamp V. Effect of four medicinal plants on amyloid- $\beta$ induced neurotoxicity in SHSY5Y cells. Afr J Trad Complement Altern Med 2013; 10: 6-11.

41. Seoposengwe K, van Tonder JJ, Steenkamp V. In vitro neuroprotective potential of four medicinal plants against rotenone-induced toxicity in SH-SY5Y neuroblastoma cells. BMC Complement Altern Med 2013; 13: 353.

42. Bastida J, Berkov S, Torras L, Pigni NB, de Andrade JP, Martínez V, Codina C, Viladomat F.. Chemical and biological aspects of Amaryllidaceae alkaloids. In: Munoz-Torrero $D$ (ed.). Recent advances in pharmaceutical sciences. Transworld Research Network, Trivandrum; 2011. p. 65-100.

43. Kumar S, Pandey AK. Chemistry and biological activities of flavonoids: An overview. The Scientific World Journal 2013; Article ID 162750.

44. Piironen V, Lindsay DG, Miettinen TA, Toivo J, Lampi AM. Plant sterols: Biosynthesis, biological function and their importance to human nutrition. J Sci Food Agr 2000; 80: 939-966.

45. Awad AB, Fink CS. Phytosterols as anticancer dietary components: Evidence and mechanism of action. J Nutrition 2000; 130: 2127-2130.

46. Li X-C, Jacob MR, Khan SI, Ashfaq MK, Babu KS, Agarwal AK, El Sohly HN, Manly SP, Clark AM. Potent in vitro antifungal activities of naturally occurring acetylenic acids. Antimicrobial Agents Chemoth 2008; 52: $2442-2448$

47. Nair JJ, Machocho AK, Campbell WE, Brun R, Villadomat $F$, Codina C, Bastida J. Alkaloids from Crinum macowanii. Phytochem 2000; 54: 945-950.

48. Elgorashi EE, van Staden J. Bioactivity and bioactive compounds of African Amaryllidaceae. In: Juliani HR, Simon JE, Ho C-T (eds.). African natural plant products: New discoveries and challenges in chemistry and quality. American Chemical Society, Washington; 2009. p. 151-170.

49. Heinrich M. Galanthamine from Galanthus and other Amaryllidaceae: Chemistry and biology based on traditional use. In: Cordell GA (ed.). The alkaloids: Chemistry and biology. Academic Press, London; 2010. p. 157-166.

50. Muchuweti M, Kativu E, Mupure $\mathrm{CH}$, Chidewe $C$, Ndhlala AR, Benhura MAN. Phenolic composition and antioxidant properties of some spices. Am J Food Technol 2007; 2: 414-420

Trop J Pharm Res, November 2016; 15(11): 2505 
51. Bhandare AM, Kshirsagar $A D$, Vyawahare NS, Hadambar AA, Thorve VS. Potential analgesic, antiinflammatory and antioxidant activities of hydroalcoholic extract of Areca catechu L. nut. Food Chem Toxicol 2010; 48: 3412-3417.

52. Likhitwitayawuid K, Angerhofer CK, Chai H, Pezzuto JM, Cordell GA. Cytotoxic and antimalarial alkaloids from the bulbs of Crinum amabile. J Nat Prod 1993; 56: 1331 1338.

53. Adesanya SA, Olugbade TA, Odebiyi OO, Aladesanmi $J A$. Antibacterial alkaloids in Crinum jagus. Int $J$ Pharmacogn 1992; 30: 303-307.
54. van Wyk B-E, van Heerden $F$, van Oudtshoorn $B$. Poisonous plants of South Africa. Briza Publications, Pretoria; 2005.

55. Verdcourt B, Trump EC. Common poisonous plants of East Africa. Collins, London; 1969.

56. Campbell WE, Nair JJ, Gammon DW, Codina C, Bastida $J$, Viladomat $F$, Smith PJ, Albrecht CF. Bioactive akaliods from Brunsvigia radulosa. Phytochemistry 2000; 53: 587-591.

57. Li Y, Liu J, Tang LJ, Shi YW, Ren W, Hu WX. Apoptosis induced by lycorine in KM3 cells is associated with the G0/G1 cell cycle arrest. Oncol Rep 2007; 17: 377-384. 